\title{
LOWER BODY PEAK FORCE BUT NOT POWER IS AN IMPORTANT DISCRIMINATOR OF ELITE SENIOR RUGBY LEAGUE PLAYERS
}

\author{
Jarrod Wade ${ }^{1,2}$, Joel Fuller ${ }^{2}$, Paul Devlin², and Timothy L.A Doyle ${ }^{2}$ \\ ${ }^{1}$ South Sydney Rabbitohs Rugby League Club, Sydney, NSW, Australia \\ ${ }^{2}$ Faculty of Medicine, Health, and Human Sciences, Macquarie University, \\ Sydney, NSW, Australia
}

Original scientific article

DOI: $10.26582 / \mathrm{k} .52 .1 .14$

\begin{abstract}
:
This investigation determined differences in lower body strength and power between elite junior (17-20 years) and elite senior (open-aged) rugby league athletes. Twenty junior and 25 senior athletes performed an isometric mid-thigh pull, countermovement jump, repeated jump, and broad jump tests during a National Rugby League pre-season. The effects of age (junior vs. senior) and position (adjustables vs. hit-up forwards vs. outside backs) on test results were investigated using a two-way analysis of variance. Cohen's d effect sizes (ES) and 95\% confidence intervals were calculated for pairwise comparisons. Isometric mid-thigh pull absolute peak force was greater for senior players compared to junior players $(E S=0.88, p<.05)$. Countermovement jump absolute peak power was greater for outside backs $(E S=1.12)$ and hit-up forwards $(E S=1.23)$ compared to adjustables $(p<.05)$, greater for senior outside backs compared to junior outside backs $(E S=1.53, p<.05)$, and greater for junior hit-up forwards compared to senior hit-up forwards $(E S=1.00, p<.05)$. This research demonstrated the differences in strength and power of rugby league athletes between playing age and position. Improving lower body strength should be prioritised for athletic development of junior rugby league athletes, with consideration given to requirements across different playing positions.
\end{abstract}

Key words: sport science, elite sport, exercise, biomechanics

\section{Introduction}

Rugby league is an intermittent team sport played internationally by junior- and senior-aged participants at both an amateur and professional level. Physical attributes such as muscular strength and power, speed, agility, and aerobic endurance have long been considered important factors in the success of individual players in rugby league (Baker \& Newton, 2008; Gabbett, 2002; Johnston, Gabbett, \& Jenkins, 2014). Additionally, there are some studies that have reported the differences between positions at the elite level by looking at utilities or adjustables (ADJ), hit-up forwards (HUF), and outside backs (OB) (Ballard, 2016; Comfort, Graham-Smith, Matthews, \& Bamber, 2011; McLellan, Lovell, \& Gass, 2011).

Previous research on physical attributes in rugby league has focused on strength and power profiling of senior-aged athletes only. Baker and Newton (2008) found that elite-level players were $17 \%$ stronger in a one-repetition maximum (1RM) squat and $12 \%$ more powerful in a weighted jump squat when compared to semi-professional players. Based on these findings, it was determined that lower body strength and power were likely to be important determinants of individual success in rugby league (Baker \& Newton, 2008). Additionally, Comfort et al. (2011) compared playing positions and showed that OB players generated greater relative peak force during an isometric squat test and greater power during a 40-kg weighted jump squat than HUF players. These results suggest that different player positions in rugby league require different strength and power attributes (Comfort et al., 2011).

Lower body strength and power testing is commonplace in elite sports; however, there are a wide variety of strength and power tests used. The 1RM squat has previously been shown as an important measure for lower body strength with strong associations to sprinting and jumping performance (Comfort, Haigh, \& Matthews, 2012; Styles, Matthews, \& Comfort, 2016). However, when comparing reliability between experienced and inexperienced participants, Ritti-Dias, Avelar, 
Salvador, and Cyrino (2011) showed a significant learning effect in those with limited resistance training experience. As a result, the isometric mid-thigh pull has come into favour as an alternate assessment of maximal strength as it requires limited training experience to complete the test (Dos Santos, et al., 2017a; Dos Santos, Thomas, Jones, McMahon, \& Comfort, 2017b). Jump testing protocols including countermovement jump, horizontal broad jump, and drop jumps have previously been used to assess lower body power across different athletes in different age categories with varying levels of weight training experience (Ball \& Zanetti, 2012; Focke, et al., 2013). In rugby league however, there is limited literature available that has used these tests to assess lower body strength and power.

Therefore, the purpose of this study was to determine whether lower body strength and power is different between elite junior (aged 17-20 years) and elite senior (open-aged) professional rugby league athletes across different playing positions. It was hypothesised that senior players would demonstrate greater lower body strength and power than junior players. Positional differences were also expected, with OBs displaying greater lower body power than HUFs, and HUFs displaying greater lower body strength than OBs.

\section{Methods}

\section{Research design}

A cross-sectional research design assessed lower body strength and power characteristics of rugby league players across age groups and playing positions. The tests conducted were: isometric mid-thigh pull, countermovement jump, repeated jump, and broad jump. Participants were assessed in the middle of the pre-season period and had completed their usual pre-season training programs prior to testing. Participants' regular weekly training programs consisted of 3-4 field sessions (including football specific skills, speed, and conditioning elements) and 4-5 weights sessions ( 2 x lower body and 2-3 $x$ upper body); frequency varied according to the period of the pre-season and athlete-specific prescription. The content of the training programs was individualised by football and strength and conditioning staff, with emphasis placed on improving rugby league specific performance.

\section{Participants}

Twenty junior-aged elite rugby league players (junior) who competed in the elite junior National Youth Competition (age: $19.2 \pm 2.0$ [range 17.6 -20.0 years]) and 25 senior-aged rugby league players (senior) who competed in the elite professional National Rugby League (age: $24.8 \pm 3.8$ [range 20.5-32.9 years]) were recruited. Participants were split into three player groups: ADJ (junior $\mathrm{n}=4$, senior $\mathrm{n}=6$ ), HUF (junior $\mathrm{n}=8$, senior $\mathrm{n}=12$ ), and OB (junior $\mathrm{n}=8$, senior $\mathrm{n}=$ 7), as determined by their usual playing position during matches. The Macquarie University Human Research Ethics Committee approved the project and all athletes provided written informed consent (protocol no. 5201600731). Junior participants were in an elite development pathway program and had a minimum one-year experience with strength and power training. Senior participants had a minimum of three years experience in strength and power training in elite sport. All participants were free from injury and completed all team training sessions in the three weeks prior to testing.

\section{Procedures}

Junior athletes were tested in the afternoon and senior athletes in the morning, before any other training had been completed on that day. A warm-up protocol consisting of foam rolling, dynamic stretching, and jumping exercises was completed before each testing session.

\section{Lower body strength}

Lower body strength was assessed using an isometric mid-thigh pull, conducted on a 400 -series force plate and mid-thigh pull rig (Fitness Technology, Adelaide, Australia). Participants stood on the force plate with knees slightly bent and held a fixed bar using an overhand grip at mid-thigh position (mid-point between the top of the patella and iliac crest). Participants were instructed to maintain a neutral spine while maximally pushing their feet into the force plate and pulling up on the fixed bar. Verbal encouragement was given by the assessor to ensure maximal effort was achieved. The realtime force trace from commercially available software (Ballistic Measurement System; Innervations, Perth, WA, Australia) was used by the tester to instruct the participant to finish the test when there was a considerable drop in maximum force output. Participants were blinded to the force trace. Each participant performed two maximum efforts with three minutes of rest between tests. Strength performance was assessed using the Ballistic Measurement System software and reported in absolute $(\mathrm{N})$ and relative $(\mathrm{N} / \mathrm{kg})$ force units. The test with the highest absolute force output was used for analysis. Previously, peak force measured in the isometric mid-thigh pull has been shown to have good reliability $(\mathrm{ICC}=.86, \mathrm{CV}<7 \%$ ) (Thomas, Dos Santos, Comfort, \& Jones, 2017).

\section{Lower body power}

Lower body power was assessed using a vertical countermovement jump, conducted on a 400 -series force plate (Fitness Technology, Adelaide, Australia). 
Participants placed a lightweight wooden stick across their shoulders to eliminate arm swing and were instructed to jump as high as possible. Each participant performed two maximum effort jumps with a two-minute rest between each jump. Power was calculated using commercially available software (Ballistic Measurement System; Innervations, Perth, WA, Australia) and reported in absolute (W) and relative $(\mathrm{W} / \mathrm{kg})$ power output. The test with the highest absolute power output was used for analysis. This test has previously been shown to exhibit excellent reliability $(\mathrm{ICC}=.98, \mathrm{CV}<2 \%$ ) for measuring peak power (Thomas, et al., 2017)

\section{Repeated vertical jump performance}

Repeated vertical jump performance was assessed using five repeat-effort jumps on a portable contact mat (Kinematic Measurement System; Innervations, Perth, WA, Australia). Participants started the test standing on the contact mat, with their hands on their hips to eliminate arm swing. They were instructed to jump as high as they could on the first jump, then immediately complete further four jumps, focusing on minimising time spent on the ground in between each take-off and maximising the height of each jump. Each participant completed two tests with two minutes between each test. Analysis was completed on the mean of the five jumps using contact time and flight time in milliseconds (ms), and the ratio between the two variables (Reactive Strength Index; RSI). The test with the highest mean value was used for further analysis. Cormack, Newton, McGuigan, and Doyle (2008) showed marginal reliability using the test to assess flight:contact times (CV 13.3\%).

\section{Horizontal jump performance}

Horizontal jump performance was assessed using a standing horizontal broad jump. Participants started the test with the heels of their shoes at the $0 \mathrm{~cm}$ mark of a tape measure fixed to the ground and instructed to jump as far as possible, utilising arm swing and landing on two feet. A jump was only successful if the participant landed in one movement, with no extra hops, or movements required for balance. Each participant performed two maximum effort jumps with a two-minute rest between each jump. Measurement to the nearest $\mathrm{cm}$ was taken from the heel that was closest to the start line on landing. The longest jump was used for analysis. Reliability for this test has been shown to be near perfect $(\mathrm{IC}=.98, \mathrm{CV}=1.8 \%$ ) (Thomas, et al., 2017).

\section{Statistical analyses}

Statistical analysis was performed using SPSS (v24, IBM, NY, USA) with significance set at an alpha level of 0.05 . The effects of player group (junior vs. senior) and position (ADJ vs. HUF vs.
OB) on the lower body strength, power, and jump performance were investigated using a two-way analysis of variance. Where significant interactions or main effects were found, post-hoc pairwise comparisons were made using the least significant difference method. Data are presented as mean \pm standard deviation. Cohen's d effect sizes (ES) and $95 \%$ confidence intervals were calculated for pairwise comparisons and reported as $\mathrm{ES} \pm 95 \%$ confidence interval. Effect sizes were considered trivial $(<.20)$, small (.20-.49), moderate (.50-.79) or large ( $\geq .80)$ (Cohen, 1973).

\section{Results}

Mean body height (ADJ: $1.79 \mathrm{~m} \pm 0.31 \mathrm{~m}$; HUF: $1.90 \mathrm{~m} \pm 0.45 \mathrm{~m}$; OB: $1.85 \mathrm{~m} \pm 0.04 \mathrm{~m})$ and body mass $(\mathrm{ADJ}=86.6 \mathrm{~kg} \pm 4.9 \mathrm{~kg}, \mathrm{HUF}=107.0 \mathrm{~kg} \pm 9.8 \mathrm{~kg}$, $\mathrm{OB}=96.0 \mathrm{~kg} \pm 8.0 \mathrm{~kg}$ ) were different between playing positions $(\mathrm{p}<.001)$. There were no statistically significant differences in height and body mass between junior (height: $1.85 \mathrm{~m} \pm 0.58 \mathrm{~m}$; body mass: $96.6 \mathrm{~kg} \pm 11.7 \mathrm{~kg} ; \mathrm{p}=.945$ ) and senior (height: $1.86 \mathrm{~m} \pm 0.65 \mathrm{~m}$; body mass: $101.0 \mathrm{~kg} \pm 11.2 \mathrm{~kg}$; $\mathrm{p}=.149)$ athletes.

Mean and standard deviation for all test results are presented in Table 1.

\section{Lower body strength}

There was a main effect of player group $(p=.006)$ and player position $(\mathrm{p}=.003)$ but no interaction of group*position $(\mathrm{p}=.818)$ on absolute lower body peak force in the isometric mid-thigh pull. Differences were observed between senior $(3833 \mathrm{~N})$ and junior $(3244 \mathrm{~N})$ players $(\mathrm{p}=.006)$ and HUF $(3913$ $\mathrm{N})$ and ADJ $(3159 \mathrm{~N})$ players $(\mathrm{p}=0.001)$. Effect sizes and $95 \%$ confidence intervals for lower body strength in the isometric mid-thigh pull are presented in Table 2.

There was a main effect of player group $(p=.043)$ but not position $(p=.969)$ or interaction of group*position $(\mathrm{p}=.787)$ on relative lower body peak force in the isometric mid-thigh pull. Differences were observed between senior $(38.0 \mathrm{~N} / \mathrm{kg})$ and junior $(34.7 \mathrm{~N} / \mathrm{kg})$ players $(\mathrm{p}=.043)$.

\section{Lower body power}

There was a main effect of player position $(\mathrm{p}=<$ $0.001)$ but not group $(\mathrm{p}=.607)$ or a group* position interaction $(\mathrm{p}=.006)$ on absolute lower body power. ADJ $(4985 \mathrm{~W})$ produced less absolute power than OB (5781 W) $(\mathrm{p}=.002)$ and HUF $(5862 \mathrm{~W})$ $(\mathrm{p}=0.001)$. Senior OB $(6184 \mathrm{~W})$ were more powerful than junior OB $(5429 \mathrm{~W})$ in absolute power measures $(p=.025)$. For HUF, juniors $(6271 \mathrm{~W})$ demonstrated greater absolute lower body power than senior players $(5590 \mathrm{~W})(\mathrm{p}=.022)$. Effect sizes and $95 \%$ confidence intervals for lower body power in the countermovement jump are presented in Table 2. 
Table 1. Lower body strength and power test results (mean \pm SD) by playing positions and age

\begin{tabular}{|c|c|c|c|c|c|c|}
\hline & \multicolumn{2}{|c|}{ CMJ Power } & \multicolumn{2}{|c|}{ IMTP Force } & \multirow{2}{*}{$\begin{array}{c}\text { Repeat Jump } \\
\text { Flight time (ms) / } \\
\text { contact time (ms) }\end{array}$} & \multirow{2}{*}{$\begin{array}{c}\text { Broad Jump } \\
\text { (cm) }\end{array}$} \\
\hline & $\begin{array}{l}\text { Absolute } \\
\text { (W) }\end{array}$ & $\begin{array}{c}\text { Relative } \\
\text { (W/kg) }\end{array}$ & $\begin{array}{l}\text { Absolute } \\
\text { (N) }\end{array}$ & $\begin{array}{c}\text { Relative } \\
(\mathrm{N} / \mathrm{kg})\end{array}$ & & \\
\hline Senior & $5633 \pm 665$ & $56.4 \pm 7.3$ & $3833 \pm 675^{b}$ & $38.0 \pm 4.7^{b}$ & $2.32 \pm 0.38$ & $282 \pm 18$ \\
\hline Junior & $5649 \pm 875$ & $58.8 \pm 7.9$ & $3329 \pm 410^{b}$ & $34.7 \pm 4.1^{\mathrm{b}}$ & $2.45 \pm 0.41$ & $289 \pm 16$ \\
\hline ALL & $5640 \pm 756$ & $57.4 \pm 7.5$ & $3609 \pm 621$ & $36.5 \pm 4.7$ & $2.38 \pm 0.39$ & $284 \pm 17$ \\
\hline Senior OB & $6184 \pm 571^{b}$ & $62.4 \pm 5.9^{a}$ & $3801 \pm 400^{\mathrm{ac}}$ & $38.4 \pm 4.9$ & $2.48 \pm 0.44$ & $286 \pm 21$ \\
\hline Junior OB & $5429 \pm 417^{b}$ & $58.8 \pm 5.1$ & $3244 \pm 419^{c}$ & $34.7 \pm 4.1$ & $2.55 \pm 0.19$ & $290 \pm 11$ \\
\hline ALL OB & $5781 \pm 615^{\mathrm{a}}$ & $57.4 \pm 7.5$ & $3504 \pm 489$ & $36.4 \pm 4.7$ & $2.45 \pm 0.41$ & $288 \pm 16^{a}$ \\
\hline Senior HUF & $5590 \pm 456^{b}$ & $52.2 \pm 4.5^{\mathrm{ac}}$ & $4127 \pm 759^{a c}$ & $38.2 \pm 4.8$ & $2.13 \pm 0.24$ & $285 \pm 14^{c}$ \\
\hline Junior HUF & $6271 \pm 932^{b}$ & $59.9 \pm 10.8^{c}$ & $3591 \pm 255^{c}$ & $34.2 \pm 3.4$ & $2.42 \pm 0.51$ & $295 \pm 19^{c}$ \\
\hline ALL HUF & $5862 \pm 747^{\mathrm{a}}$ & $55.2 \pm 8.3$ & $3913 \pm 656^{a}$ & $34.7 \pm 4.1$ & $2.25 \pm 0.39$ & $288 \pm 17^{\mathrm{a}}$ \\
\hline Senior ADJ & $5077 \pm 690$ & $57.8 \pm 8.5$ & $3283 \pm 395^{a}$ & $37.2 \pm 4.8$ & $2.51 \pm 0.41$ & $271 \pm 19^{c}$ \\
\hline Junior ADJ & $4846 \pm 634$ & $57.7 \pm 7.4$ & $2974 \pm 368$ & $35.7 \pm 6.2$ & $2.34 \pm 0.58$ & $272 \pm 10^{c}$ \\
\hline ALL ADJ & $4985 \pm 642^{\mathrm{a}}$ & $57.7 \pm 7.6$ & $3159 \pm 396^{a}$ & $36.6 \pm 5.2$ & $2.44 \pm 0.46$ & $272 \pm 16^{a}$ \\
\hline
\end{tabular}

Note. $\mathrm{CMJ}=$ countermovement jump, IMTP = isometric mid-thigh pull, OB = outside backs, HUF = hit-up forwards, ADJ = adjustables . All values represented as mean \pm SD. ${ }^{a}$ Significant difference $(p<.05)$ between playing positions. ${ }^{b}$ Significant difference $(p<.05)$ between age groups. ${ }^{c}$ Significant difference $(p<.05)$ between playing positions by age groups.

Table 2. Effect size and 95\% confidence intervals for pairwise comparisons for countermovement jump and isometric mid-thigh pull

\begin{tabular}{lcccc}
\hline & \multicolumn{2}{c}{ CMJ Power } & \multicolumn{2}{c}{ IMTP Force } \\
& Absolute (W) & Relative (W/kg) & Absolute (N) & Relative (N/kg) \\
\hline Senior v Junior & $0.02 \pm 0.52$ & $0.16 \pm 0.30$ & $0.88 \pm 0.57^{\mathrm{a}}$ & $0.74 \pm 0.67^{\mathrm{a}}$ \\
OB v HUF & $0.11 \pm 0.68$ & $0.66 \pm 0.67$ & $0.69 \pm 0.60$ & $0.02 \pm 0.69$ \\
OB v ADJ & $1.12 \pm 0.73^{\mathrm{a}}$ & $0.37 \pm 0.91$ & $0.76 \pm 0.94$ & $0.04 \pm 0.79$ \\
HUF v ADJ & $1.23 \pm 0.68^{\mathrm{a}}$ & $0.31 \pm 0.69$ & $1.29 \pm 0.69^{\mathrm{a}}$ & $0.02 \pm 0.76$ \\
\hline Senior OB v HUF & $1.19 \pm 1.20^{\mathrm{a}}$ & $2.01 \pm 1.34^{\mathrm{a}}$ & $0.50 \pm 0.75$ & $0.06 \pm 0.92$ \\
Senior OB v ADJ & $1.76 \pm 1.11$ & $0.65 \pm 1.11$ & $1.30 \pm 1.44^{\mathrm{a}}$ & $0.24 \pm 1.07$ \\
Senior HUF v ADJ & $0.95 \pm 1.16$ & $0.92 \pm 1.20$ & $1.27 \pm 0.77^{\mathrm{a}}$ & $0.19 \pm 0.97$ \\
\hline Junior OB v HUF & $1.17 \pm 0.87$ & $0.20 \pm 0.85$ & $1.00 \pm 1.49$ & $0.13 \pm 1.25$ \\
Junior OB v ADJ & $1.18 \pm 1.56$ & $0.08 \pm 1.49$ & $0.67 \pm 1.56$ & $0.21 \pm 1.19$ \\
Junior HUF v ADJ & $1.67 \pm 0.90$ & $0.22 \pm 0.88$ & $2.10 \pm 2.83$ & $0.34 \pm 1.30$ \\
\hline Senior v Junior OB & $1.53 \pm 1.32^{\mathrm{a}}$ & $0.76 \pm 1.34$ & $1.36 \pm 1.30^{\mathrm{a}}$ & $0.82 \pm 1.08$ \\
Senior v Junior HUF & $1.00 \pm 0.84^{\mathrm{a}}$ & $1.01 \pm 0.86^{\mathrm{a}}$ & $0.87 \pm 0.76^{\mathrm{a}}$ & $0.90 \pm 0.99$ \\
Senior v Junior ADJ & $0.35 \pm 1.21$ & $0.00 \pm 1.15$ & $0.80 \pm 1.73$ & $0.28 \pm 1.12$ \\
\hline
\end{tabular}

Note. $\mathrm{CMJ}=$ countermovement jump, IMTP = isometric mid-thigh pull, $\mathrm{OB}=$ outside backs, HUF = hit-up forwards, ADJ = adjustables. All values represented as effect size $\pm 95 \%$ confidence intervals. ${ }^{a}$ Significant differences $(p<.05)$ between the groups.

For relative lower body peak power in the countermovement jump, there were no main effects of player group $(\mathrm{p}=.608)$ or player position $(\mathrm{p}=.234)$ or group*position interaction ( $\mathrm{p}=.056)$.

\section{Repeated vertical jump and horizontal jump performance}

For repeated jump performance, there were no main effects of playing position $(\mathrm{p}=189)$ or group $(\mathrm{p}=.605)$, or group*position interaction $(\mathrm{p}=.340)$ on reactive strength index in the repeat effort jump test. For horizontal jump performance, there was a main effect of playing position ( $\mathrm{p}=.025)$ but not playing group $(\mathrm{p}=.335)$ in the horizontal broad jump. There was no group* position interaction $(\mathrm{p}=.781)$. HUF $(288 \mathrm{~cm})(\mathrm{ES}=0.99 \pm 0.80, \mathrm{p}=.009)$ and $\mathrm{OB}(288$ $\mathrm{cm})(\mathrm{ES}=1.01 \pm 0.86, \mathrm{p}=.024)$ showed greater distance in the broad jump test than ADJ $(272 \mathrm{~cm})$.

\section{Discussion and conclusions}

The aim of this research was to compare the lower body strength and power profiles of elite senior and junior rugby league players. Consistent with the main hypothesis, senior players were 
stronger in the isometric mid-thigh pull than junior players across both the absolute (13\% greater) and relative ( $10 \%$ greater) force production. However, in contrast to the hypothesis, there was no overall difference between junior and senior players for absolute $(<1 \%$ difference $)$ and relative $(<4 \%$ difference) lower body power in the countermovement jump. However, lower body power differed within playing positions of different age groups, with the senior OB demonstrating greater absolute lower body power than the junior OB (14\% greater) and the junior HUF demonstrating greater absolute lower body power than the senior HUF $(12 \%$ greater).

These findings supported existing literature saying that lower body strength is a discriminator of elite senior rugby league players (Baker \& Newton, 2008; Till, Jones, Darrall-Jones, Emmonds, \& Cooke, 2015). Baker and Newton (2008) found $12-17 \%$ differences in absolute lower body strength in a 1RM squat between elite and sub-elite rugby league players. The present findings suggest that there is a similar 13\% difference in absolute isometric mid-thigh pull strength between elite senior and junior rugby league players. Similarly, Ireton, Till, Weaving, and Jones (2017) used the isometric mid-thigh pull and observed a $14 \%$ difference in absolute strength between under-19 and senior rugby league players. Therefore, developing lower body strength in junior rugby league athletes appears to be important for effectively preparing them to transition to elite senior-grade competition.

Existing literature investigating lower-body power differences in junior- and senior-aged players is equivocal. Gabbett (2002) demonstrated 27-28\% differences in lower body power between under-19 and senior players across different playing positions. In contrast, Ireton et al. (2017) found that senior players were not more powerful in the countermovement jump than junior players $(<8 \%$ difference). The current research did not demonstrate differences in countermovement jump power between junior and senior athletes $(<4 \%$ differences). However, there were notable differences between junior and senior athletes from different playing positions. Senior OB demonstrated 14\% greater absolute lower body power than junior
$\mathrm{OB}$, whilst also demonstrating $11 \%$ greater relative lower body power than senior HUF. These results were somewhat expected because previous research showed senior OB achieve greater maximum speed, sprint distance, and complete a greater number of sprint efforts than junior-aged OB during rugby league match play (Ballard, 2016; McLellan \& Lovell, 2013). The present findings demonstrate the importance of position specific lower body power for rugby league players, specifically $\mathrm{OB}$.

Unexpectedly, and in contrast to $\mathrm{OB}$, the junior HUF demonstrated $12 \%$ greater absolute lower body power than the senior HUF during the countermovement jump test. The different results between OB and HUF positional groups could be attributed to the added focus on increasing upper body mass and strength to senior HUF players. Research has shown HUF players are required to complete more collisions, tackles, and wrestling than OB in rugby league matches (Johnston, et al., 2014; McLellan, et al., 2011). These increased wrestling demands require HUF to have high-levels of upper body strength and body mass to enhance this technical element of the game. The added focus on increased upper body mass and strength could have a negative effect on jump and sprint performance. In the countermovement jump test, the increased upper body strength provides minimal direct benefit to jump performance and the additional upper body mass impedes vertical acceleration during the jump. It is important for practitioners to continue to develop the lower body strength and power of HUFs to ensure the ability to move their body mass is not diminished to a level that will affect their match performance.

Overall, the research indicates the main discriminator between junior and senior rugby league players is lower body strength. Therefore, improving lower body strength should be the main priority for any athletic development program targeting junior rugby league athletes transitioning into the senior ranks. Consideration must be given to the requirements of the different playing positions within rugby league when focusing on other physical qualities within the development program. OB players require more specific lower body power development within the training program.

\section{References}

Baker, G.D., \& Newton, U.R. (2008). Comparison of lower body strength, power, acceleration, speed, agility, and sprint momentum to describe and compare playing rank among professional rugby league players. Journal of Strength and Conditioning Research, 22(1), 153-158. doi: 10.1519/JSC.0b013e31815f9519

Ball, N.B., \& Zanetti, S. (2012). Relationship between reactive strength variables in horizontal and vertical drop jumps. Journal of Strength and Conditioning Research, 26(5), 1407-1412. doi: 10.1519/JSC.0b013e3182510870

Ballard, D. (2016). Positional benchmarking and team selection based on physical qualities in elite rugby league. Journal of Australian Strength and Conditioning, 24(5), 6-15. 
Cohen, J. (1973). Eta-squared and partial eta-squared in fixed factor ANOVA designs. Educational and Psychological Measurement, 33(1), 107-112. doi: 10.1177/001316447303300111

Comfort, J.P., Graham-Smith, J.P., Matthews, J.M., \& Bamber, J.C. (2011). Strength and power characteristics in English elite rugby league players. Journal of Strength and Conditioning Research, 25(5), 1374-1384. doi: 10.1519/JSC.0b013e3181d687f5

Comfort, J.P., Haigh, J.A., \& Matthews, J.M. (2012). Are changes in maximal squat strength during preseason training reflected in changes in sprint performance in rugby league players? Journal of Strength and Conditioning Research, 26(3), 772-776. doi: 10.1519/JSC.0b013e31822a5cbf

Cormack, S.J., Newton, R.U., McGuigan, M.R., \& Doyle, T.L.A. (2008). Reliability of measures obtained during single and repeated countermovement jumps. International Journal of Sports Physiology and Performance, 3(2), 131-144. doi: 10.1123/ijspp.3.2.131

Dos Santos, T., Thomas, C., Comfort, P., McMahon, J.J., Jones, P.A., Oakley, N.P., \& Young, A.L. (2017a). Betweensession reliability of isometric mid-thigh pull kinetics and maximal power clean performance in male youth soccer players. Journal of Strength and Conditioning Research, 32(12), 3364-3372. doi: 10.1519/JSC.0000000000001830

Dos Santos, T., Thomas, C., Jones, P.A., McMahon, J.J., \& Comfort, P. (2017b). The effect of hip joint angle on isometric midthigh pull kinetics. Journal of Strength and Conditioning Research, 31(10), 2748-2757. doi: 10.1519/ JSC.0000000000002098

Focke, A., Strutzenberger, G., Jekauc, D., Worth, A., Woll, A., \& Schwameder, H. (2013). Effects of age, sex and activity level on counter-movement jump performance in children and adolescents. European Journal of Sport Science, 13(5), 518-526. doi: 10.1080/17461391.2012.756069

Gabbett, T.J. (2002). Physiological characteristics of junior and senior rugby league players. British Journal of Sports Medicine, 36(5), 334-339. doi: 10.1136/bjsm.36.5.334

Ireton, M.R.E., Till, K., Weaving, D., \& Jones, B. (2017). Differences in the movement skills and physical qualities of elite senior and academy rugby league players. Journal of Strength and Conditioning Research. doi: 10.1519/ JSC.0000000000002016

Johnston, R., Gabbett, T., \& Jenkins, D. (2014). Applied sport science of rugby league. Sports Medicine, 44(8), 10871100. doi: 10.1007/s40279-014-0190-X

McLellan, C.P., \& Lovell, D.I. (2013). Performance analysis of professional, semiprofessional, and junior elite rugby league match-play using Global Positioning Systems. Journal of Strength and Conditioning Research, 27(12), 3266-3274. doi: 10.1519/JSC.0b013e31828f1d74

McLellan, C.P., Lovell, D.I., \& Gass, G.C. (2011). Performance analysis of elite rugby league match play using Global Positioning Systems. Journal of Strength and Conditioning Research, 25(6), 1703-1710. doi: 10.1519/ JSC.0b013e3181ddf678

Ritti-Dias, M.R., Avelar, P.A., Salvador, S.E., \& Cyrino, S.E. (2011). Influence of previous experience on resistance training on reliability of One-Repetition Maximum Test. Journal of Strength and Conditioning Research, 25(5), 1418-1422. doi: 10.1519/JSC.0b013e3181d67c4b

Styles, J.W., Matthews, J.M., \& Comfort, J.P. (2016). Effects of strength training on squat and sprint performance in soccer players. Journal of Strength and Conditioning Research, 30(6), 1534-1539. doi: 10.1519/JSC.0000000000001243

Thomas, C., Dos Santos, T., Comfort, P., \& Jones, P.A. (2017). Between-session reliability of common strength- and power-related measures in adolescent athletes. Sports, 5(1), 15. doi: 10.3390/sports5010015

Till, K.A., Jones, B., Darrall-Jones, J., Emmonds, S., \& Cooke, C. (2015). Longitudinal development of anthropometric and physical characteristics within academy rugby league players. Journal of Strength and Conditioning Research, 29(6), 1713-1722. doi: 10.1519/JSC.0000000000000792

Submitted: September 24, 2018

Accepted: May 7, 2019

Published Online First: May 15, 2020
Correspondence to:

Timothy Doyle, Ph.D.

Department of Health Professions

Faculty of Medicine, Health, and Human Sciences

Macquarie University

Office: + 61298509841

Mobile: + 61411551744

E-mail: tim.doyle@mq.edu.au

\section{Acknowledgements}

The authors acknowledge the support of players, coaches, and staff of South Sydney Rabbitohs Rugby League Club for their efforts in allowing the research to take place. There was no financial assistance involved with undertaking this project. 